\title{
Mate choice screening in captive solitary carnivores: The role of male behavior and cues on mate preference and paternity in females of a model species, American mink (Neovison vison)
}

\author{
Christina Lehmkuhl Noer ${ }^{1,2}$ (D) | Thorsten Johannes Skovbjerg Balsby ${ }^{3}$ | \\ Razvan Anistoroaei $^{4}$ | Mikkel Stelvig ${ }^{1}$ | Torben Dabelsteen ${ }^{2}$
}

${ }^{1}$ Research and Conservation, Copenhagen Zoo, Frederiksberg, Denmark

2 Department of Biology, Behavioural Ecology Group, University of Copenhagen, København, Denmark

${ }^{3}$ Department of Bioscience, Aarhus University, Aarhus, Denmark

${ }^{4}$ Section of Genetics, Bioinformatics and Systems Biology, Faculty of Health and Medical Sciences, Department of Veterinary Clinical and Animal Sciences, University of Copenhagen, København, Denmark

\section{Correspondence}

Christina Lehmkuhl Noer, Research and

Conservation, Copenhagen Zoo,

Frederiksberg, Denmark.

Email: cln@zoo.dk

\section{Funding information}

Innovation Fund Denmark, Grant number: 12-122917
Mate choice studies suggest that choosy females benefit from increased fecundity, litter size, and offspring survival. Thus, providing females with the opportunity to choose among potential mates, deemed genetically suitable based on studbook data, might improve breeding management in production and zoo animals and thereby the sustainability of captive populations. Investigating mate preference via odor from potential mates before animal transfer is a proposed strategy for incorporating mate choice into breeding management. In this study, we test whether olfactory cues and signals from males can be used to assess and measure female mate preference in American mink. Eighteen females were subjected to a 4-day stimulus test in which females showed a preference for one of two males' urine and feces. Subsequently, each female was subjected to a 10-day mate preference test involving the same two males of the first test. Paternity tests revealed that 13 females had offspring, which could be assigned to only one male, suggesting that these females performed a mate choice. In nine of these females preference during the stimulus test was directed toward the male that fathered their offspring. Our results suggest that even though there was a preference difference in scent stimulus trials from potential mates this preference was not predictive of eventual mate preference or paternity. Other factors such as aspects of male behavior seem to play a role, when the mates are introduced. Our study supports that mate preference and mate choice are complex matters influenced by multiple cues and signals.

\section{KEYWORDS}

American mink, breeding success, mate choice, mate preference, olfaction

\section{1 | INTRODUCTION}

Breeding problems are common in several captive carnivore species (Díez-León et al., 2013; Martin-Wintle et al., 2015) like the endangered European mink (Mustela lutreola) (Kiik, Maran, Nagl, Ashford, \& Tammaru, 2013), the black-footed ferret (Mustela nigripes) (Wolf et al., 2000), the giant panda (Ailuropoda melanoleuca) (Martin-Wintle et al., 2015;
Zhang, Swaisgood, \& Zhang, 2004), the cheetah (Acinonyx jubatus) (Baker, Pullen, \& Pullen, 2013), and other felids (Mellen, 1991). Incorporating mate choice in breeding management is a proposed strategy to minimize these problems and improve breeding success (Asa, Traylor-Holzer, \& Lacy, 2011; Martin-Wintle et al., 2015). Mate choice is a component of most mating systems and providing individuals with a selection of potential mates and thereby the opportunity to choose the "preferred" 
one could possibly optimize breeding success and improve the sustainability of captive populations (Asa et al., 2011). The role of mate choice in mating strategies and reproductive success has been investigated in many different species including mammals (Clutton-Brock \& McAuliffe, 2009), birds (Andersson \& Simmons, 2006), and fish (Berejikian, Tezak, \& LaRae, 2000). These and other studies have shown increased fecundity, litter size, and offspring survival as well as increased animal welfare as a result of introducing mate choice (Asa et al., 2011; Drickamer, Gowaty, \& Holmes, 2000; Roberts \& Gosling, 2004). The increased welfare might occur as a result of increased mate compatibility and reduced aggression when allowing females to mate with preferred males (Dingemanse, Both, Drent, \& Tinbergen, 2004; Dingemanse \& Réale, 2005; Sih \& Watters, 2005; Watters \& Powell, 2011).

Multiple mechanisms might influence an individual's choice of breeding partner, for example, visual, olfactory, and auditory signals and cues from potential breeding partners as well as competition among conspecifics, available resources, etc. (Asa et al., 2011; Jennions $\&$ Petrie, 1997). Some of these cues and signals offer an opportunity to test female preference for mates in captivity before transfer and then only transfer the preferred male. This could be particularly relevant for solitary carnivores, which are troublesome to transfer and keep together in large enough numbers to provide an actual choice between mates.

Olfactory communication plays an important role in solitary carnivores particularly during the breeding season and mate choice (Gorman \& Trowbridge, 2013). Individual chemical signals from glandular secretions found in, for example, urine and feces provide information on an individual's reproductive state (Swaisgood, Lindburg, Zhou, \& Owen, 2000) and qualities (Roberts \& Gosling, 2003, 2004). Receivers of these signals will often react by investigating the area where the scent has been marked, countermark, and potentially becoming aroused (Berzins \& Helder, 2008). Whether or not such subsequent behavior occurs depends on the information content of the signals, the context as well as the significance of the odor to the receiver (Berzins \& Helder, 2008). In solitary mustelid species, such as the stoat (Mustela ermine) and domestic ferret (Mustela putorius furo), olfactory familiarity is suggested to be present between neighboring males and females due to anal scent marking activities in their home ranges (Clapperton, 1989; Erlinge, Sandell, \& Brinck, 1982). Furthermore, studies on rodents have shown that females recognize the major histocompatibility complex (MHC) and identify potential males through odor cues, preferring to mate with males with dissimilar MHC genes (Penn \& Potts, 1999; Roberts \& Gosling, 2004; Thom \& Hurst, 2004). Berzins and Helder (2008) have shown that the domestic ferret is able to distinguish between familiar and unfamiliar male conspecifics via olfactory cues. Olfactory signals have been proven honest signals of male quality (Roberts \& Gosling, 2004; Zahavi, 1975) and cues and signals from urine and feces appear to be important in mate choice decisions of mustelids.

American mink (Neovison vison) are a good model species for solitary carnivores (Dallaire, Meagher, \& Mason, 2012; Thom, Macdonald, \& Mason, 2004). They live in solitude in relatively large home ranges, which they mark with urine and feces. Males are territorial, but their territory often overlaps with home ranges of several females (Dunstone, 1993). Female home ranges overlap only with that of one male or their young daughters. Despite this spatial separation females often produce multiple sired litters (Thom et al., 2004; Yamaguchi, Sarno, Johnson, O'Brien, \& Macdonald, 2004). The American mink are seasonal breeders and male transience is expected to provide the opportunity for multiple matings during the breeding season (Thom et al., 2004). Multiple matings by females, that is, polyandry, can be explained due to genetic benefits. A female may choose to mate with transient healthy and strong males with different immunological genes from her own thus conferring a wider array of immune defense to her offspring as found in mice (Roberts \& Gosling, 2003). Multiple matings with different males can hence increase the genetic diversity of offspring and thereby their chance of survival (Clutton-Brock \& McAuliffe, 2009; Thom et al., 2004). Females exhibiting polyandry may, however, still perform mate choices in order to secure the largest genetic benefits. Other studies have shown that females with polyandry can be choosy, for example, females of the meadow vole (Microtus pennsylvanicus) (Berteaux, Bêty, Rengifo, \& Bergeron, 1999), the Malagasy carnivore the fossa (Cryptoprocta ferox) (Hawkins \& Racey, 2009) and the cheetah (Mossotti, 2010). Female behavior and physiology of the American mink suggests mate choosiness (Thom et al., 2004). Female mink exhibit delayed and variable implantation of their ova, which enable fertilization by multiple males. Furthermore, their ovulation is induced making it hard to predict fertilization (Sundqvist, Amador, \& Bartke, 1989). This might benefit the females by enabling post-copulatory cryptic female choice for either certain genotypes and sperm characteristics or superior sperm as suggested in, for example, the fossa (Birkhead \& Møller, 1993; Lührs \& Kappeler, 2014). We, therefore, expect the female mink to mate with more males if given a choice as found by Thom et al. (2004). At the same time, we expect the females to show a preference for specific male cues and signals if these cues and signals honestly indicate varying quality in males. In this study we define female preference as cases where females show an active interest by sniffing and scratching more to urine and feces from one male as well as visiting or mating more or longer with one particular male than others in contexts of free choice, and this is independent of whether or not mating lead to conception (Clutton-Brock \& McAuliffe, 2009). Female mate choice, on the other hand, is defined by the actual paternity of her offspring. Paternity is a measure of mating success, which includes all levels of potential sexual selection from pre- to post-copulatory mechanisms, where the female could potentially exercise a mate choice in this polyandrous species. We hypothesize that female mink should be choosy if available males differ in quality. Since mink have only been bred in captivity in evolutionary short time, for slightly more than 100 years (Dansk Pelsdyravlerforening et al., 1961; Seton, 1909), their ability to assess potential mates using their sense of smell as well as other senses is most likely unimpaired.

Signals and cues other than olfactory are likely to play a role in female mate preference in fact the use of multiple cues and signals is 
probably universal (Jennions \& Petrie, 1997). Studies on other species suggest that behavior reflecting aspects of animal personality might influence mate choice or reproductive success (MartinWintle et al., 2017; Sih \& Watters, 2005; Watters \& Powell, 2011), for instance, due to increased compatibility and assortative mating (Dingemanse et al., 2004; Dingemanse \& Réale, 2005; Forstmeier \& Birkhead, 2004; Sih \& Watters, 2005; Watters \& Powell, 2011). Females may prefer specific personality traits of their mates if the behavior associated with these mates' personality makes them better at surviving (David, Auclair, \& Cézilly, 2011), more successful in mating competitions or less likely to cause damage to the female during mating. Inter-sexual selection may also play a role in maintaining the sexual size dimorphism in mink suggesting that females might have a preference for larger males (Thom et al., 2004).

The aim of this study is threefold: (1) screening for females' interest in olfactory stimuli from males of farmed American mink. We simultaneously present each female with two unfamiliar males' urine and feces and investigate if there is a difference in amount of time the female spends sniffing to each sample. (2) Investigate whether this stimulus preference is reflected in the female's mate preference directed toward two males in a successive free choice test where the female can choose to visit and mate with the same two males that provided the olfactory stimuli. (3) Investigate whether the female's stimuli and mate preference is reflected in the actual mate choice measured as the paternity of her offspring.

We furthermore wanted to investigate whether aspects of personality correlated with female mink preference (using the shyness-boldness continuum reviewed by Wilson, Clark, Clark, Coleman, \& Dearstyne, 1994). We, therefore, tested female preference against aspects of the shyness-boldness continuum, measured in a nonsocial novel object test and a social mirror test early in the breeding season in a previous study by (Noer, Needham, Wiese, Balsby, \& Dabelsteen, 2016). In addition, we tested whether females were more likely to choose mates (measured as paternity) with personalities similar to their own as described in other species, for example, zebra finches (Taeniopygia guttata) and giant panda (David et al., 2011; Martin-Wintle et al., 2017). We also tested for a female preference for larger males although this has not been found in previous studies of American mink (Díez-León et al., 2013; Thom et al., 2004).

To the best of our knowledge, this is the first study to investigate whether urine and feces can be used to measure a mate preference in female American mink. The potential influence of aspects of animal personality on female preference and choice will also be investigated for the first time in the American mink. We expect to be able to record a difference in the time the female spends assessing the two males' urine and feces and hence a stimulus preference. We furthermore expect this stimulus preference to correlate with a female preference for visiting and mating more with the preferred male, although other male cues and signals such as size and aspects of animal personality might have an effect on this mate preference. Finally, we expect that some of these measures of female preference can predict paternity of her offspring.

\section{2 | METHODS}

\section{1 | Study animals and housing}

Sixty adult wild-type American mink, 20 females and 40 males, were tested at the research farm Rørrendegård, Taastrup, Denmark. All individuals were farm-reared, approximately 10 months old, and sexually inexperienced when tested during the breeding season in late February and March 2014. Before the experiment all subjects were housed individually in identical standard wire-mesh farm cages (W: $30 \mathrm{~cm} \times \mathrm{H}: 45 \mathrm{~cm} \times \mathrm{L}: 90 \mathrm{~cm}$ ), connected to a wooden nest box with wire-mesh and straw on top ( $W: 28 \mathrm{~cm} \times \mathrm{H}: 20 \mathrm{~cm} \times \mathrm{L}: 23 \mathrm{~cm}$ ) (Figures $1 \mathrm{a}$ and $1 \mathrm{~b}$ ). Each cage was part of a series of six contiguous cages, joined at the longest side. The cages of males and females were located in different barns and, therefore, without visual contact. Drinking water was provided ad libitum via a nipple drinker on a water pipe. All

(a)

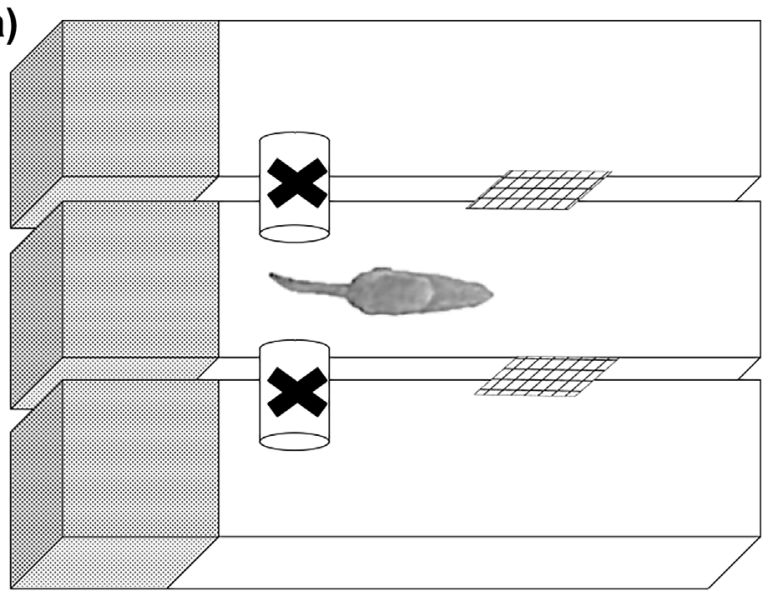

(b)

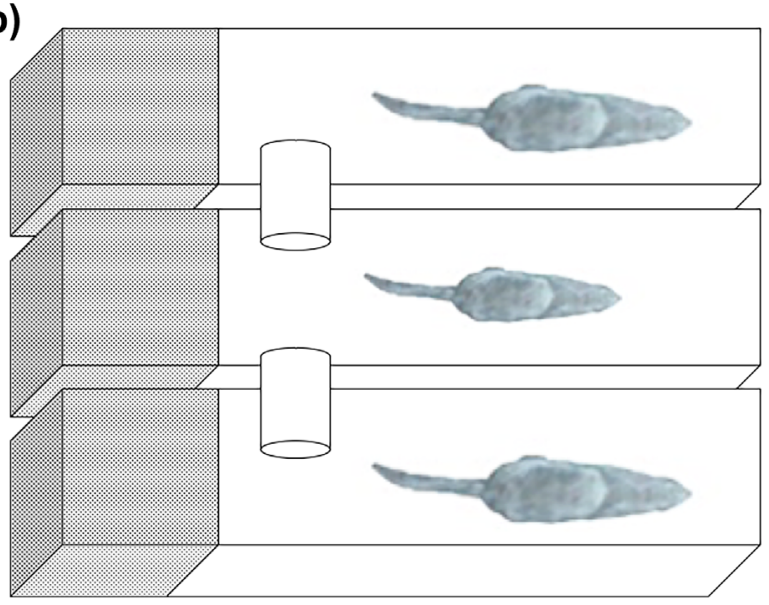

FIGURE 1 ( $a$ and $b$ ) Test setup in ( $a$ ) the stimulus preference test where the female mink in the middle cage is presented to scent samples from two different males. The scent samples are presented on either side of the outside of the female's cage (illustrated by the square mesh stimulus presenters). The entrance tubes to the neighboring cages are closed. Test setup in (b) the mate preference test where the female mink in the middle cage gains access to the two different males in the neighboring cages through the access tubes for $3 \mathrm{hr}$ a day 
animals were fed a standard meat-based feed once per day after $4 \mathrm{pm}$. From the 27th of February and onward the feed amount had been modified near to ad libitum in order to prepare the mink for breeding. Excess feed was removed temporarily during testing. Lighting conditions were programmed to switch on and off automatically, providing a constant light intensity from sunrise to sunset. The average temperature during the two experiments was 4 and $6^{\circ} \mathrm{C}$, respectively.

\section{$2.2 \mid$ Behavioral tests}

The female subjects were transferred to their test cages on the 20th of February. The cages were distributed on both sides of a two-row open barn divided by an aisle. The preference tests consisted of two phases: a 4-day stimulus preference test (25-28 February) and a subsequent 10-day mate preference test (3-14 March).

\subsection{1 | Stimulus preference test}

Each female was presented with fresh urine and feces samples from two males once a day in a 30-min test. Urine and feces for a trial were collected for approximately $24 \mathrm{hr}$ on floor cards $(H: 61.5 \mathrm{~cm} \times \mathrm{L}$ : $28.8 \mathrm{~cm}$ ) covering the floor of two males' cages. Kit net was placed on top to avoid the males from reaching the floor card. After removal from the male cages the floor cards were left for $1 \mathrm{hr}$ to avoid too fresh odors, before they were folded and placed in separate wire-mesh stimuli presenters, each with a plastic-tube below to collect excess urine or feces (W: $1.5 \mathrm{~cm} \times H: 42 \mathrm{~cm} \times \mathrm{L}: 20.5 \mathrm{~cm}$ ). These presenters were mounted to the outside of either side of the female's cage at the middle of the longest sides (Figure 1a). One day prior to test start each female was subjected to two empty stimuli presenters for $30 \mathrm{~min}$ in order to familiarize with these. The four trials were carried out between 9 am and $2 \mathrm{pm}$ and balanced so that each female was tested at a different time each day. To balance for a potential female preference for side, fresh stimuli from the two males was presented right or left, respectively, every second day during the 4 days. Individuals were tested in a random order using a balanced design. Trials performed on the same time of day were at least two cages away from individuals being tested on the same day, and at least a series of six cages away from those tested at the same time. Since olfaction is a highly developed sense in mustelids it is likely that the females are able to smell conspecifics located meters away. However, similar to Berzins and Helder (2008), we assume that the females are unfamiliar with the presented male odors, before the test, in the sense that they are unable to recognize one specific male from the mix of odors they perceive from all individuals.

\subsection{2 | Mate preference test}

During this test, each side of the female's cage were fitted with an entrance hole ( $D: 64,66$, or $68 \mathrm{~mm})$ in a plastic tube $(D: 10 \times L: 19.5 \mathrm{~cm})$ providing her with free access to visit the two potential mates placed in the neighboring cages (Figure $1 \mathrm{~b}$ ). The entrance holes were custom made to each female exploiting the sexual dimorphism of the mink
(Díez-León et al., 2013; Dunstone, 1993) so that the females could pass through the holes while the larger males could only get their heads through. These holes were blocked with solid inserts between trials. Before the mate preference test females were given 3 days to familiarize with the access tubes providing them access every day. The pairing of males was done relative to the female December weight so that heavier females were exposed to heavier males. In the process of selecting males for a pair we also considered the males' shynessboldness score from a mirror test in December performed in a previous study by Noer et al. (2016), in order to ensure that each female was paired with a male with a relatively high score and a male with a relatively low score. The difference in weight and shyness-boldness score between the males of a pair was approximately the same for all females. Knowledge of kinship of the mink was used to ensure that no mating of close relatives (siblings) took place. Males were transferred to the neighboring cage of the female, where their stimuli had been presented on the last day, 3 days prior to mate preference test start. This was done in order to allow the males to familiarize with their new cage. After 5 test days, the males were shifted to the other side of the female's cage in order to balance out a potential effect of side and allowed another 3 days to familiarize with the cage. For 10 days, each female was given free access to the same two males for $3 \mathrm{hr}$ a day from $9 \mathrm{am}$ to $12 \mathrm{pm}$. No males where used in multiple preference tests.

\subsection{3 | Novelty tests and weight}

Prior to the two preference tests of this study the 60 mink were subjected to novelty tests twice, outside the breeding season in December 2013 and again in the early breeding season in February 2014 (Noer et al., 2016). This was done in order to measure aspects of their personality. Shyness-boldness was reflected in the inter-individual variation in approach behavior responses toward two different novelties: a novel object representing a non-social context and a mirror representing a social context. The approach behaviors of the mink toward the novelties were analyzed using principal component analyses. The results showed consistency in interindividual variation in shyness measures across seasons. However, like in a previous study by Noer, Needham, Wiese, Balsby, and Dabelsteen (2015) this consistency also differed across the non-social and social context, probably representing two different shynessboldness dimensions, fearfulness, and social shyness, respectively (Noer et al., 2015). All mink were weighed in December 2013 and again in March 2014 after the mate preference trials.

\subsection{4 | Paternity test and litter size}

After the last tests, a blood sample was collected from all adult mink by clipping a nail. The offspring were not blood sampled or counted until they were at least eight weeks old in late June to avoid disturbing the pups and the mother and in accordance with farm procedure. This approach provided us with recordings of the strongest offspring, capable of surviving the first critical weeks, only. The blood samples were used to extract DNA for further use in the paternity testing of the 
offspring. Genomic DNA was extracted using Qiagen Investigator Kit (\#56504). A number of 11 microsatellite markers (GAB2208, Mvi4025, Mel109, Mvi5001, Lut604, Mvi087, Mvi6017, Mvi2407, Mvi1614, Mvi4042, and Mvi4037) (Anistoroaei et al., 2012) were used for assessing the various alleles and their segregation among the investigated families. Genotyping was performed with fluorescently labeled forward primers (HEX, FAM, and NED) on an ABI Prism 3130 sequencer (Applied Biosystems, Foster City, CA), and genotypes were analyzed using GENSCAN analysis (v.3.1.2) software (Applied Biosystems). The resulting allele sizes were manually assessed and interpreted.

\section{3 | Ethics statement}

According to the Danish law regarding animal experimentation §1, the tests in this study did not require a license or special permission (The Animal Experimentation Act no. 253, March 8th 152 2013). The Danish Veterinary and Food Administration administer the experimental farm according to the Danish legislation (BEK 1428/15072002 \& BEK 1734/22122006). Animal experiments with mink have, when needed, been performed according to permit from the Danish Animal Experiment Inspectorate. Permit no. 2005/561-994. University of Copenhagen, who owned the farm, gave permission to use the animals. The housing conditions followed strictly the requirements of the Danish Animal Protection Act 2013, order no. 1734 of 2006 (Danish Ministry of Food, Agriculture and Fisheries). The nail clipping and blood sampling followed normal farm procedure and did not require a permit. No animals were harmed during the non-invasive experiments and after the experiments the animals were included in the normal farm production. The animals' health status was checked daily by the breeder and the animals were found healthy at all times except for two females who died (several days and weeks after the tests of unidentified illnesses). These females were excluded from all analyses to avoid uncertainties of preference measured during potential illness.

\subsection{Observations and measures of female preference}

\subsection{1 | The stimulus preference tests}

The stimulus preference tests were video recorded using GoPro Hero 3 Silver and Black edition cameras (๔ 2014 GoPro, Inc.) to minimize human contact. The first $20 \mathrm{~min}$ of the video recordings were analyzed using continuous recording (Martin \& Bateson, 1993) as pilot studies showed a decline in interest after 10-15 $\mathrm{min}$. The following behaviors were recorded: Sniffing day 1 and sniffing total were measured as the total time (in seconds) the female spend sniffing to each of two male samples on the first trial day and during all 4 trial days combined, respectively. Sniffing was measured when the mink's snout was touching or less than $1 \mathrm{~cm}$ away from the cage net within the area of the stimuli presenter, for at least $1 \mathrm{~s}$. Scratching was included in the behavior sniffing since no female performed scratching without having the snout one $\mathrm{cm}$ or closer to the area of the stimuli presenter.

\subsection{2 | Mate preference tests}

In the mate preference tests, instantaneous scan sampling of each female and her neighboring males was performed for $3 \mathrm{hr}$ with a sampling time interval of 6 or $4 \mathrm{~min}$. This resulted in 27 registration points (times) per female per observation day. This recording method was chosen due to limited camera availability. A total of 13 behavioral variables including female-male interactions were registered during the 10 test days. The variables are listed in Table 1 below. The preliminary analyses described below revealed which of these behavioral variables were most suitable as female mate preference measures.

Time visiting was measured as the total number of visiting scans recorded for the female visiting each of the two males during the 10 observation days, excluding mating duration (see the definition below). This was hence the most accurate estimate of the amount of time the female spent with each male (Table 1 ).

We assessed which behavioral variables that provided the best estimate of mating duration out of the two recorded (Table 1). Observations of a total of 20 video recorded matings revealed that mating duration varied with 10 shorter matings (mean $\pm S D$ : $3.5 \mathrm{~min} \pm 3.3$ ) and 10 longer matings (mean $\pm \mathrm{SD}$ : $58.8 \mathrm{~min} \pm 21.5$ ). No matings were intermediate lasting between 10 and $33 \mathrm{~min}$ suggesting that in general a mating is either short or long. A mating should last at least $6 \mathrm{~min}$ to ensure fertilization according to Adams and Rietveld (1981) and according to Danish mink breeders at least 10 min (pers. comm., Boye Pedersen, Rørrendegård research farm). Neck bite scans were easily observed and recorded and hence a more valid measure of mating duration than mating scans (Table 1). It often took some time for the male mink to get hold of the female and the video observations revealed a few examples of disrupted neck bites within the first four consecutive scans (pers. obs.). Therefore, the duration of a mating was approximated by the number of consecutive neck bite scans $\geq 4$ (minimum: $1+6+6+6 \mathrm{~min}=19 \mathrm{~min}$ ) as a conservative measure of a mating considerably longer than the $10 \mathrm{~min}$, likely to lead to fertilization. Number of neck bite scans correlated with duration of the actual matings observed on the videos (Pearson's $r=0.86$; $N=11 ; p=0.0006$ ), whereas the original measure for mating: mating scans did not (Pearson's $r=0.48 ; N=12 ; p=0.11$ ), supporting that neck bite scans is a better measure. Therefore, mating duration was estimated using the total number of neck bite scans during long matings ( $\geq 4$ consecutive neck bite scans combined during the 10 observation days).

\section{5 | Statistics}

\subsection{1 | Inter-observer reliability}

Two observers watched all video recordings of the stimulus preference test. Inter- and intra-observer reliability tests were performed before and after the observations using the Pearson (parametric data) or Spearman tests (non-parametric data). Furthermore, a t-test (parametric data) or a Mann-Whitney $U$ test (non-parametric) was used to check 
TABLE 1 The 13 female and male mink behaviors registered using scan sampling during the 3-hr mate preference tests, including female-male interactions

\begin{tabular}{|c|c|c|}
\hline $\begin{array}{l}\text { Female behaviors (noted for both } \\
\text { left and right male cages) }\end{array}$ & & $\begin{array}{l}\text { Relevance as measures of } \\
\text { female preference }\end{array}$ \\
\hline Female entering male cage & $\begin{array}{l}3 \text { stages: Female with (1) frontend, ( } 2 \text { ) backend, or ( } 3 \text { ) entire body } \\
\text { in the entrance tube moving toward male cage }\end{array}$ & $\begin{array}{l}\text { Not a certain measure of } \\
\text { female preference }\end{array}$ \\
\hline Visiting & $\begin{array}{l}\text { The female has its entire body (not necessarily the tail) inside one } \\
\text { of the neighboring male cages }\end{array}$ & $\begin{array}{l}\text { Most accurate measure } \\
\text { of time visiting }\end{array}$ \\
\hline Female leaving male cage & $\begin{array}{l}2 \text { stages: Female with frontend or backend in the entrance } \\
\text { tube leaving male cage }\end{array}$ & $\begin{array}{l}\text { Not a certain measure of } \\
\text { female preference }\end{array}$ \\
\hline \multicolumn{3}{|c|}{ Male behaviors (noted for both left and right male) } \\
\hline Male touches entrance & The male has its head in or at the entrance tube & $\begin{array}{l}\text { Not a direct measure of } \\
\text { female preference }\end{array}$ \\
\hline Male bites female & The male bites female in or at the entrance tube & $\begin{array}{l}\text { Not a direct measure of } \\
\text { female preference }\end{array}$ \\
\hline Neck bite & $\begin{array}{l}\text { The male has a firm neck bite grip and is attached to the neck of } \\
\text { the female }\end{array}$ & Measure of mating \\
\hline Mating & $\begin{array}{l}\text { The male is holding the female in a neck bite, with its hind legs } \\
\text { locked around the female. The male's back is hunched with its } \\
\text { pelvis held against the female in a position suggesting intromission. } \\
\text { Copulation is characterized by repeated pelvic thrusting, which might } \\
\text { start and stop several times until intromission is achieved, at which point } \\
\text { movement stops (Murphy \& Douglas, 1992) }\end{array}$ & Measure of mating \\
\hline \multicolumn{3}{|c|}{ Female and male behavior while visiting males (noted for both left and right male) } \\
\hline Rest & The female and male rests together or separately often after mating & $\begin{array}{l}\text { Measure included in } \\
\text { visiting scans }\end{array}$ \\
\hline Chase & $\begin{array}{l}\text { It is noted down whether it is the male or female chasing the } \\
\text { other if possible or whether it is both }\end{array}$ & $\begin{array}{l}\text { Rare. Measure included } \\
\text { in visiting scans }\end{array}$ \\
\hline Escape & $\begin{array}{l}\text { It is noted down whether it is the male or female escaping the } \\
\text { other if possible or whether it is both }\end{array}$ & $\begin{array}{l}\text { Rare. Measure included } \\
\text { in visiting scans }\end{array}$ \\
\hline \multicolumn{3}{|c|}{ General behavior (noted for both female and the two males) } \\
\hline Stereotypic & $\begin{array}{l}\text { Repetitive movements which are repeated } 5 \text { or more times without } \\
\text { interruption }\end{array}$ & $\begin{array}{l}\text { Did not seem to influence } \\
\text { female preference }\end{array}$ \\
\hline Purr & $\begin{array}{l}\text { Males make a purring sound during the mating season } \\
\text { (Dunstone, 1993) }\end{array}$ & $\begin{array}{l}\text { Not possible to identify } \\
\text { the emitter }\end{array}$ \\
\hline Scream & If an animal screams & $\begin{array}{l}\text { Not a direct measure of } \\
\text { female preference }\end{array}$ \\
\hline
\end{tabular}

The texts in bold were the ones that were deemed most suitable and accurate as female preference measures for further analyses.

for systematic differences in observations. The criteria for passing reliability tests were Pearson's and Spearman's $r \geq 0.7, p<0.05$, along with a t-test or Mann-Whitney $U$ test with $p>0.05$. The tests proved that the behavioral variables included in further analyses were reliable $p<0.05$. The two observers were unable to reach intra-observer reliability due to slight differences in the reaction time of their computers. This does, however, not influence the results as each observer observed the same females and results are not compared between females.

\subsection{2 | Analyses of data}

18 female mink were included in the analyses of female preference as data from the two females who died after the tests was excluded in order to avoid biasing the results due to a potential illness.

\section{Female preference measures}

The behavioral variables' ability to predict female preference was investigated by looking for a difference in the female stimulus and mate preference measures between the two males. The preferred males are always by definition the ones with the highest value within each behavioral preference variable. Pearson and Spearman tests were performed to look for correlations between related preference measures. Binomial tests were used to test if the proportion of females with correspondence between preference and paternity differed from random. The binomial tests were all one-tailed due to the known paternity. Paired $t$-tests were used to test if there was a difference in partner preference measures and stimulus preference measures between fathers and non-fathers. Using a t-test assuming unequal variance we tested if there was a difference in those fathers where mating duration predicted paternity and those where it did not. 
The correlations and binomial tests were analyzed in GraphPad Prism Version 6.0f or SAS ver. 9.3 using proc $t$-test.

\section{Combining measures}

We tested how the preference measures related to paternity using generalized linear models with female ID as a repeated measure. We made 11 different models combining preference measures (predictor variables) one by one in order to test their ability to explain paternity (binomially distributed response variable) using the Quasi Information Criterion (QIC). These analyses were conducted using proc genmod in SAS ver. 9.3.

Male weight and personality

The March weight (females: 1,195-1,620 g, males: 2,230-3,514 g) and the shyness scores from the February novelty tests, were included in the following analyses, as these were measured close to the breeding season in the study by Noer et al. (2016). The shyness scores were Shyness 1 and 2 in the novel object test, which may reflect fearfulness or exploration/curious approach toward novel objects, respectively (Shyness 1 and 2 novel object February), and Shyness 1 and 2 in the mirror test reflecting different aspects of social shyness in the mink directed toward their mirror image (Shyness 1 and 2 mirror February) (see Noer et al., 2016). The ability of males' shyness-boldness personality scores and weight (predictor variables) to predict partner preference was tested using a general linear model with female identity as repeated measure and an unbiased covariance structure. Similarly, the ability of males' shyness-boldness personality scores and weight (predictor variables) to predict paternity was tested using generalized linear models with binomial distribution also with female identity as the repeated measure and an unbiased covariance structure. To test the difference in shyness-boldness score between the female and each of the two males in regards to paternity a t-test was used. If the fathers have a smaller difference in shyness-boldness score compared to non-fathers, then it would indicate that the females have offspring sired by males with shyness-boldness scores more similar to themselves. For the paired $t$-tests the difference between pairs did not deviate from normal distribution for any of the parameters (Sharpiro-Wilks test $p>0.072$ ). In addition, we tested if the shyness scores of males with paternity related to female personality scores, as well as whether the difference in personalities of fathers and non-fathers related to female personalities, using generalized linear models. These analyses were also done in SAS ver. 9.3 using proc genmod, proc mixed, and proc $t$-test.

\section{3 | RESULTS}

\section{1 | Measures of female preference}

\subsection{1 | Stimulus preference tests}

In the stimulus preference tests sniffing day 1 and sniffing total during all 4 days were the variables used to measure female preference. Total time spent sniffing per observation period to both males' urine and feces samples was highest on day 1 (mean \pm SD: $167.6 \mathrm{~s} \pm 96.7 \mathrm{~s}$ ) in 15 of the 18 females. There seemed to be an overall decrease in amount of sniffing over the test period with the amount of time spent sniffing being smallest on day 4 (mean $\pm S D: 74.5 \mathrm{~s} \pm 59.0 \mathrm{~s}, N=18$ ) in 11 of the 18 females. The difference in interest, defined by differences in time sniffing, between the two male samples was the largest on day 1 (mean difference $\pm S D: 80.7 \mathrm{~s} \pm 78.2 \mathrm{~s}, N=18$ ) in 12 of the 18 females. The median difference in sniffing day 1 between preferred and nonpreferred was $28.2 \%$ (range: 0-82\%) (Figure 2a). The median difference in sniffing total between preferred and non-preferred was 11.9\% (range: 2-55\%) (Figure 2b). Some females changed their day 1 preference on 1 or more of the subsequent days (sniffing more to the other male sample), however, this noise did not affect the overall preference and repeatability in preference as indicated by the strong correlation between sniffing day 1 and sniffing total during all 4 days (Spearman's $r=0.84 ; N=18 ; p<0.0001$ ).

\subsection{2 | Mate preference tests}

In the mate preference tests two behavioral variables were used to measure female preference: Time visiting (total number of visit scans minus mating duration) and mating duration (total number of neck bite
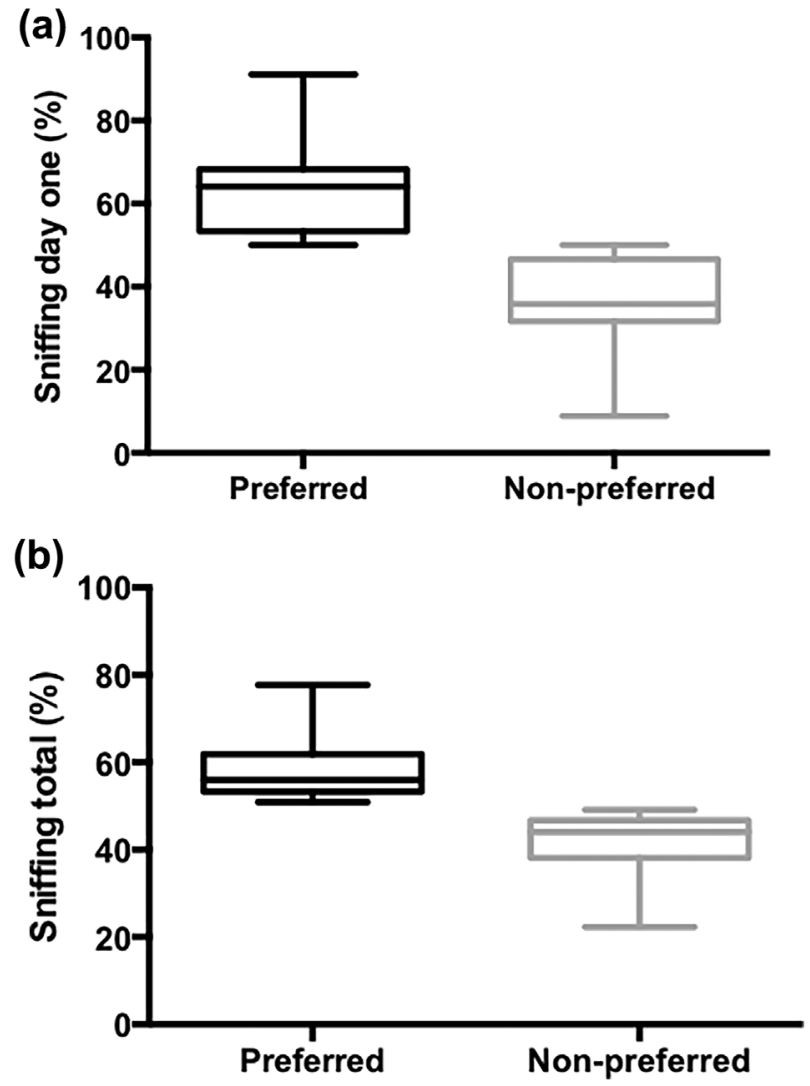

FIGURE 2 ( $a$ and $b$ ) Box plots of the difference in time spent sniffing by female mink between the preferred and the nonpreferred male sample for (a) sniffing day 1 and (b) sniffing total. Medians, $25 \%$ and $75 \%$ quartiles, and minimum and maximum values are shown 
scans during long matings). Time visiting differed between the two males in all but one of the 18 females. There was a large variation in visit scans per day within and between females. We, therefore, looked at the difference in percentage between males for total number of visit scans for all 10 days combined. The median difference in time visiting between preferred and non-preferred male was 35.9\% (range: 0-93\%) (Figure 3a). Mating duration differed between preferred and nonpreferred male in all 18 females. There was a median difference of $18.4 \%$ (range: $5-100 \%$ ) in mating duration between the preferred and non-preferred male (Figure $3 \mathrm{~b}$ ).

\subsection{Evaluation of preference measures}

In this section, we evaluate whether the stimuli preference measures sniffing day 1 and sniffing total can predict the females' willingness to visit (time visiting) and mate with (mating duration) the preferred male as well as if the stimulus and mate preference measures can predict paternity.

\subsection{1 | Stimulus preference as a predictor of mate preference and paternity}

There were no correlations between sniffing day 1 and either of the mate preference measures time visiting or mating duration (Pearson's

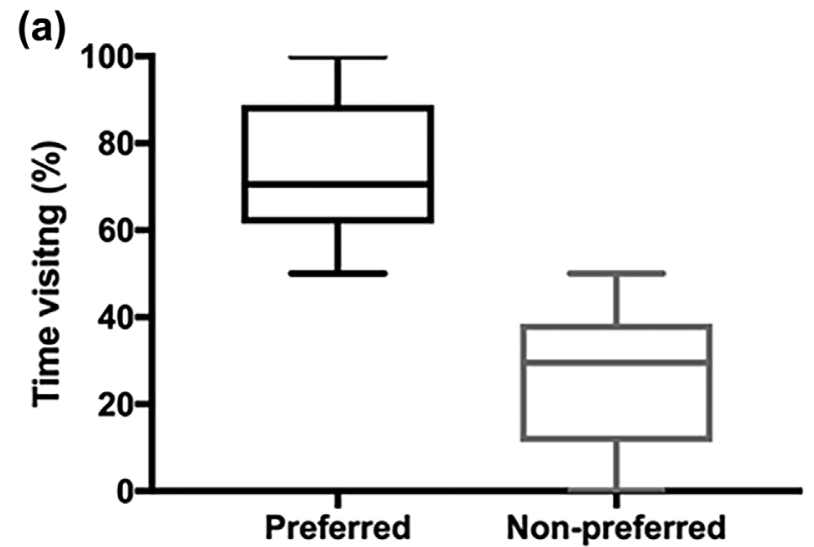

(b)

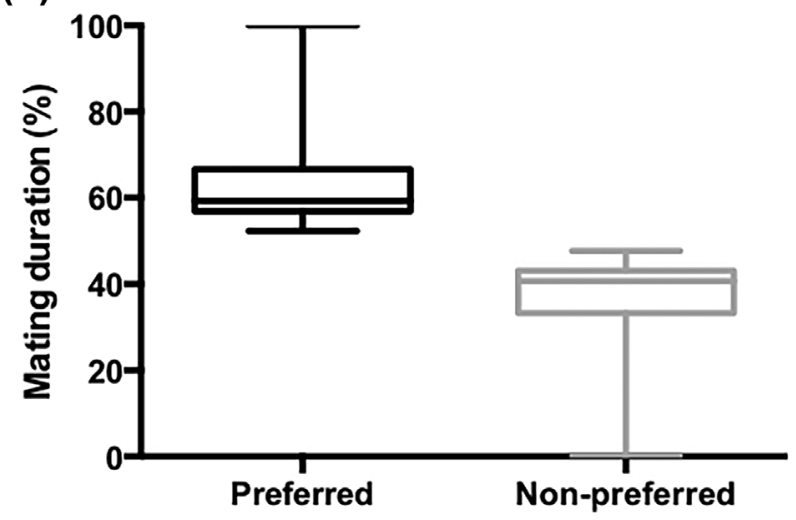

FIGURE 3 ( $a$ and $b$ ) Box plots of the difference in (a) time visiting and (b) mating duration by female mink between the preferred and the non-preferred males. Medians, $25 \%$ and $75 \%$ quartiles, and minimum and maximum values are shown $r \leq 0.30 ; N=36 ; p \geq 0.08$ ) or between total sniffing and the two mate preference measures (Pearson's $r \leq 0.13 ; N=36 ; p \geq 0.45$ ). Furthermore, we found no correlation between the mate preference measures time visiting and mating duration (Pearson's $r=0.19 ; N=36 ; p=0.26$ ).

Fifteen out of the 18 female mink gave birth to offspring that survived at least until eight to nine weeks of age: two females (13\%) had shared paternity, that is, no mate choice. These two females were excluded from further analyses of mate choice. Each of the remaining 13 females were fertilized by one male only indicating mate choice as the general rule in this experiment (13 out of 15, Binominal test, onetailed, $p=0.004$ ). Each female gave birth to one to eight pups with a mean of five pups per female (mean $\pm S D: 5 \pm 1.9$ ). The paternity results showed some interesting trends, when evaluating the stimulus preference measure sniffing day 1 and sniffing total as a predictor of paternity. In eight females (62\%) the most time spent sniffing day 1 was toward the male that became the father of her offspring (8 out of 13 , Binomial test, one-tailed, $p=0.291$ ). The predictability improved slightly if we included all 4 days (sniffing total): In nine females (69\%) the time spent sniffing total was toward the male which was the father, but this proportion was not significant either ( 9 out of 13, Binomial test, one-tailed, $p=0.133$ ) (Figure 4).

A $t$-test was used to test whether there was a significant difference in the stimulus preference measures directed toward the fathers of the offspring versus the non-fathers. We found no significant difference between non-fathers and fathers (Paired $t$-test $t_{12} \leq-1.15 ; p \geq 0.27$ ).

\subsection{2 | Mate preference as a predictor for paternity}

Mating duration could explain the paternity for nine of the females (9 out of 13 , Binomial test, one-tailed, $p=0.133$ ) whereas time visiting only could explain seven out of 13 . None of these proportions differed significantly from random. Hence neither mating duration or time visiting significantly predicted paternity (Figure 4).

A $t$-test was used to test whether there was a significant difference in the female mate preference measures directed toward the fathers of the offspring versus the non-fathers. We found a significant difference in mating duration between non-fathers and fathers (Paired $t$-test $t_{12}=-2.48 ; p=0.03$ ) with fathers having the longest mating duration. When testing the nine fathers where mating duration could explain paternity against the four fathers where it could not we found a significant difference in mating duration between the two groups ( $t$-test assuming unequal variance $t_{10,8}=-2.45 ; p=0.03$ ). With the nine fathers where mating duration could explain paternity having the longest mating duration.

\subsection{3 | Combined predictors' influence on paternity}

If including both of the two preference measures sniffing total and mating duration, which explained paternity the best, only one of 13 paternity outcomes could not be explained by either of the two (12 out of 13 , Binomial test, one-tailed, $p=0.002$ ). We tested the different preference measures' ability to explain paternity using generalized 


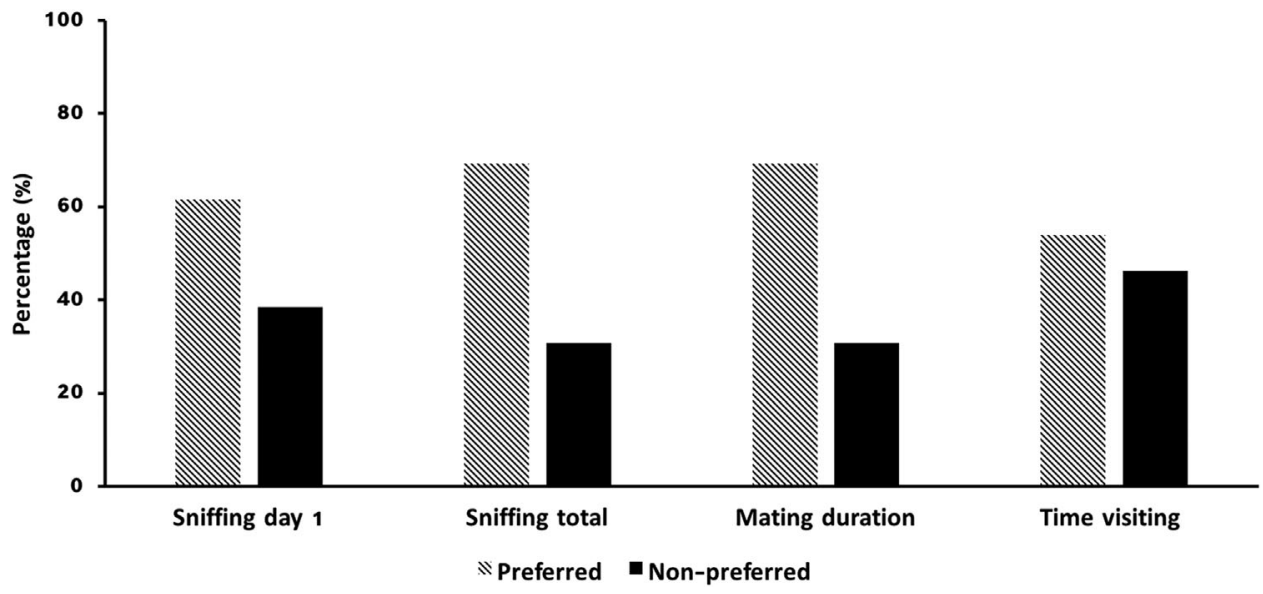

FIGURE 4 Female mink preference. The female preference measures (sniffing day 1, sniffing total, mating duration, and time visiting) ability to predict the preferred male in the paternity test of the 13 female mink who performed a mate choice

linear models with a binomial distribution, with female ID as repeated measure. We performed 11 different models including one of the four different preference measures: sniffing day 1, sniffing total, time visiting, and mating duration as initial predictor variables and constructed models with additional preference measures in order to investigate whether the stimulus preference measures in combination with one or more of these mate preference measures (additional predictor variables) or alone could predict paternity and hence female mate choice (Table 2). The two best models explaining the probability of the male to become a father according to Quasi Information Criterion (QICu) included only mating duration or mating duration and sniffing total. Both models showed a positive but non-significant relation between mating duration and paternity (Generalized linear model mating duration: $\chi_{1}{ }^{2}=2.60, p=0.107$, slope $=0.012$, model with sniffing total and mating duration; mating duration: $\chi_{1}{ }^{2}=2.34$, $p=0.126$, slope $=0.011$, sniffing total: $\chi_{1}{ }^{2}=0.05, \quad p=0.831$, slope $=-0.0001)$. These two models were, however, only a marginally better fit than the other models with two or more parameters (Table 2).

\section{3 | Male qualities as predictors of paternity or compatibility}

Male qualities such as size and behavior might also affect female preference and choice. We, therefore, tested the ability of males' shyness-boldness personality scores and weight (predictor variables) to predict paternity and partner preference, respectively (response variables). There were no significant results for paternity except for a tendency for Shyness 2 novel object February, which related negatively with paternity (Generalized linear model with binomial distribution $\chi_{1}{ }^{2}=3.42 ; p=0.06$; slope $=-1.03$ ). When testing the ability of males' shyness-boldness personality scores and weight (predictor variables) to predict the partner preference measures we only found that Shyness 1 novel object February predicted a longer mating duration (General linear model with repeated measures $F_{1,10}=19.50 ; p=0.001 ;$ slope $=7.12$ ).
$T$-tests revealed that females did not choose males with personalities more similar to themselves. The difference in shyness scores between the female and each of the males (Shyness 1 novel object February or Shyness 1 and 2 mirror February) did not vary between fathers and non-fathers ( $t$-test $t_{10} \leq 0.79 ; p \geq 0.445$ ). Neither did the three shyness scores of males with paternity relate to the females' shyness scores (General linear model $F_{1,14} \leq 1.30 ; p \geq 0.27$ ). And the difference in personalities of fathers and non-fathers did not relate to female personalities (General linear model $F_{7,7} \leq 3.36 ; p \geq 0.11$ ).

\section{4 | Polyandry and timing of matings}

All 18 females visited both males. The females visited males on average eight out of 10 possible days (mean \pm SD: $8.4 \pm 2.5$ days). Each female engaged in an average of six matings (measured as $\geq 4$ consecutive scans with neck bite) (mean \pm SD: $6.2 \pm 3.0$ ). The females mated on one to nine of the 10 days available with a mean of 5 mating days (mean \pm SD: $4.7 \pm 2.2$ ) per female. Only one female did not mate with both males and she did not sire any offspring.

When looking at the timing of matings we found that 12 out of 18 females mated with both males during the same day on 1 or more days. The number of females mating declined after the first 3 days but increased again after the break (Figure 5). One to seven females mated with both males on the same day, on each of day 1-3 and day 8-11 only, with a peak in females mating on day 3 after test start (mean \pm SD: $3.3 \pm 2.1$ females) (Figure 5).

\section{4 | DISCUSSION}

This study confirms that female mink do choose between different males if given a choice in captivity. However, mate choice is complex and seems to be based on many cues and signals and cannot be determined solely on preference tests for urine and feces as all but one female mink chose to mate with both males. Our results suggest that male urine and feces can be used to measure female preference of 
TABLE 2 QIC-values for possible models including sniffing, time visiting and mating duration

\begin{tabular}{|c|c|c|c|c|c|c|c|c|c|c|}
\hline \multirow[b]{2}{*}{ Model } & \multirow[b]{2}{*}{ QIC } & \multicolumn{3}{|l|}{ Sniffing } & \multicolumn{3}{|c|}{ Time visiting } & \multicolumn{3}{|c|}{ Mating duration } \\
\hline & & Estimate & $x^{2}$ & $p$ & Estimate & $x^{2}$ & $p$ & Estimate & $x^{2}$ & $p$ \\
\hline S1 & 41.72 & -0.0002 & 0.04 & 0.834 & & & & & & \\
\hline ST & 41.46 & 0.0002 & 0.17 & 0.676 & & & & & & \\
\hline $\mathrm{ST}+\mathrm{MD}$ & 40.84 & -0.0001 & 0.05 & 0.831 & & & & 0.0113 & 2.34 & 0.126 \\
\hline $\mathrm{S} 1+\mathrm{TV}$ & 42.47 & 0.0003 & 0.08 & 0.782 & 0.014 & 0.80 & 0.371 & & & \\
\hline $\mathrm{S} 1+\mathrm{TV}+\mathrm{MD}$ & 41.68 & -0.0004 & 0.13 & 0.714 & 0.012 & 0.80 & 0.370 & 0.0098 & 2.21 & 0.137 \\
\hline $\mathrm{ST}+\mathrm{TV}$ & 42.33 & -0.000 & 0 & 0.976 & 0.014 & 0.88 & 0.347 & & & \\
\hline $\mathrm{ST}+\mathrm{TV}+\mathrm{MD}$ & 41.63 & -0.0002 & 0.11 & 0.738 & 0.013 & 1.01 & 0.314 & 0.009 & 2.32 & 0.128 \\
\hline
\end{tabular}

The $\chi 2$ reports the type 3 of the GEE analysis. Note that sniffing was measured as sniffing day 1 and as total sniffing over 4 days. Sniffing day 1 (S1), sniffing total (ST), time visiting (TV), and mating duration (MD). The best models are marked in bold.

mates in farmed American mink as all 18 female mink sniffed more to the urine and feces of the one of two males during a 4-day two choice stimulus preference test. However, more cues and signals seem to play an important role when the mates are introduced. Therefore, introducing urine before transferring males might help give the females a choice as well as make them familiar to the males before introduction, which has proven important in other species such as the harvest mouse (Micromys minutus) (Roberts \& Gosling, 2004) and the pygmy loris (Nycticebus pygmaeus) (Fisher, Swaisgood, \& Fitch-Snyder, 2003). However, our study also suggests the importance of introducing the actual males in mate choice studies in order to provide the females with more cues and signals to choose from.

This kind of mate preference test where a female can choose between two unfamiliar male odors has to our knowledge never been carried out on American mink before. Our results are supported to some extent by a study on another mustelid species, the domesticated

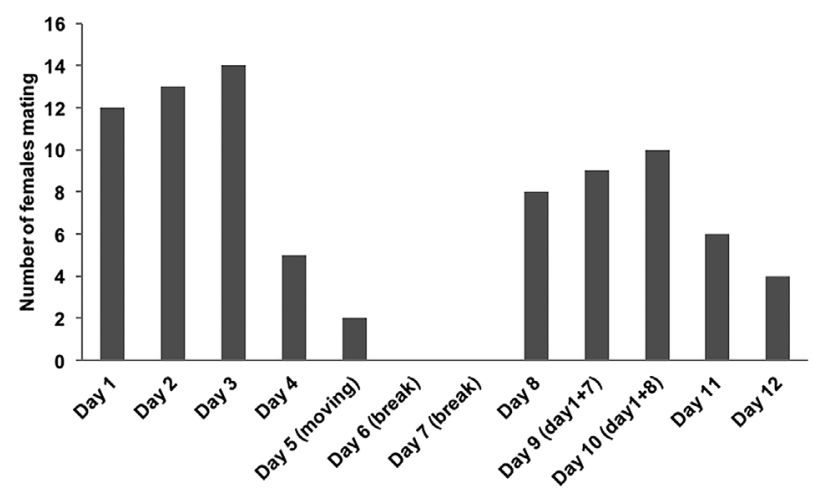

FIGURE 5 Number of female mink mating per day during the mate preference test. The peak mating days for each test period of 5 days are on days 3 and 10, which are estimated days for ovulation (48 hr after first mating and with 7 days interval for 3 weeks) in the female American mink with their first mating on day 1 ferret (Cloe, Woodley, Waters, Zhou, \& Baum, 2004), which showed that a combination of volatile body odors, including anal scent gland secretions and urinary odors underlie olfactory sex discrimination and partner preference. Time spent sniffing is a common measure of preference in similar studies on cheetahs (Mossotti, 2010), rodents (Roberts, Davidson, Beynon, \& Hurst, 2014), and primates (Fisher et al., 2003). Furthermore, approaching and proximity to odors have also been used as a measure of preference in studies of ferrets (Berzins \& Helder, 2008; Cloe et al., 2004). We found that the amount of time spent sniffing on the first day of the test (sniffing day 1) and in total during the 4-day test period (sniffing total) differed between the two male samples in all but one female, indicating a female preference. The one female with no difference in time spent sniffing between the two different male samples on the first trial day, turned out to have shared paternity of its offspring in the subsequent paternity analyses. These results suggest that urine can be introduced before transfer in order to provide cues for the female to initially base a mate choice on as well as ensure familiarity.

As expected, we found that the female interest in the odor stimuli declined over time, but that the preference for the male odor stimuli on the first trial day correlated with the preference during all 4 days combined confirming repeatability. Berzins and Helder (2008) also recorded a decrease in interest with repetition of test days in domestic ferrets. The females in our study spend $168 \pm 97$ (mean \pm SD) seconds sniffing to both samples on the first day of the trial, which is only $14 \%$ of the time available. This is in line with other studies of solitary carnivores (Berzins \& Helder, 2008; Mossotti, 2010). These results combined suggest that even shorter presentations of males' urine and feces might be sufficient to measure a female preference.

Stimulus preference, that is, urine and feces preference, could not predict the female's willingness to visit and mate with each male, as there was no correlation between the measures sniffing day 1 or sniffing total and the two mate preference measures: time visiting and 
mating duration. These results indicate as expected that the female mink might use additional cues and signals, that is, other than odor, when assessing males, and that these additional cues and signals might alter the preference in some individuals. Alternatively, these results suggest that some females actively choose to mate with both males making the two mate preference measures less likely to predict mate choice, which is also a likely explanation in this polyandrous species.

For all but one of the 18 females we found that time visiting and mating duration differed between the two males. Thus, these two measures could potentially be used as a measure of female mate preference. Berzins and Helder (2008) measured a significant difference in female ferrets' spatial occupation toward different males as well as in females' chemosensory contact, sniffing and licking males, through the mesh-netting separating females from males. Proximity is a simple measure of preference that has been used in previous mink studies (Díez-León et al., 2013; Thom et al., 2004). Thom et al. (2004) suggested that there could be a difference between social preferences and mating preferences in American mink as they found that the male, which the female spent most time visiting, differed from the one that the female spent most time mating with. They suggested that their results indicate that female social preference of males might not be a valid indicator for sexual preference in mink. In accordance with Thom et al. (2004) we found that time visiting males did not correlate with mating duration.

\subsection{Female preference measures ability to predict paternity}

Paternity is a measure of mating success, which includes all levels of potential inter-sexual selection from pre- to post-copulatory mechanisms, where the female could potentially exercise a mate choice. Therefore, we defined mate choice by the paternity of this polyandrous species' offspring and we evaluated the ability of the stimulus and mate preference measures to predict paternity, that is, the ultimate mate choice. We were able to register a mate choice in 13 out of 15 females, who conceived offspring. Because paternity tests revealed that these 13 females had pups fathered by only one male despite the fact that all but one of these females visited and mated with both males. Similar to other carnivores, female mink show multiple paternity in captivity and in the wild (Thom et al., 2004; Yamaguchi et al., 2004). The paternity of this study revealed, however, interestingly, mate choice as the general pattern in this study. This could indeed represent post-copulatory cryptic choice, but it could also merely reflect male fertility or other male-specific factors. For the stimulus preference measures we were able to explain paternity of the offspring of eight out of 13 females when using the measure sniffing day 1 and of nine out of 13 females when using sniffing total. When comparing the mate preference measures with paternity we found somewhat similar results: mating duration could explain nine out of 13 of the paternity results. Whereas time visiting could only explain seven out of 13 females' paternity. Hence, each preference measure alone explained between $54-69 \%$ of females' paternity. When combining the two preference measures sniffing total and mating duration, which explained paternity the best, 12 out of 13 paternity outcomes could be explained by either or both of the two. Interestingly, the paternity analysis in our study revealed that mate choice may be the general pattern in this species despite the fact that all but one female visited and mated with both available males.

$T$-tests comparing the females' stimulus and mate preference measures directed toward fathers and non-fathers showed no difference in sniffing day 1 , sniffing total, or in time visiting, but did show a significant difference in mating duration between fathers and non-fathers. The nine fathers where mating duration could explain paternity had the longest mating duration suggesting that the four fathers where mating duration could not explain paternity had less of a difference in mating duration. These results indicate that the females might be able to have an effect on the outcome of multiple matings with more males and thereby the paternity by directing more time toward mating with a preferred male. A high number of matings are thought to increase fertility assurance (Birkhead \& Møller, 1993) as multiple copulations might ensure fertilization of more female eggs (Hunter, Petrie, Otronen, Birkhead, \& Møller, 1993). Therefore, number of matings may be a mechanism by which polyandrous females can control paternity by repeated matings with the same male (Clutton-Brock \& McAuliffe, 2009). Furthermore, longer mating duration has been found to increase sperm competition (Hawkins \& Racey, 2009). Hence longer matings with one of the males is expected to improve that male's chance of fertilization. If mating duration is under female control it might be a way for her to bias paternity toward the preferred male (Clutton-Brock \& McAuliffe, 2009; Thom et al., 2004) in a male dominated mating system where more transient males might mate with the same female. On the other hand, if mating duration is under male control this can also be a way for the males to improve their chances of fertilization.

By giving the females a choice between males, we provide them with multiple cues and signals that can be used to assess males, including male behavior and phenotype. Unfortunately, little is known about how females differentiate and value the cues and signals used during mating and courtship (Jennions \& Petrie, 1997). The use of multiple cues and signals in mate choice is, however, expected to be universal (Jennions \& Petrie, 1997). Since the females are likely to base their choice of a preferred partner on more cues and signals we combined both stimulus and mate preference measures of females in a model in order to investigate whether a combination of these could be used to predict paternity. We found that the best models explaining the probability of the male to become the father included either mating duration or a combination of sniffing total and mating duration. Both of these parameters had a positive relation to paternity as expected, suggesting that a way that the females might be able to control paternity and perform mate choice might be by controlling the mating duration with each male although none of these models were significant. 


\subsection{Male qualities as predictors of paternity or compatibility}

During the mate preference test the females have multiple cues and signals available to assess males on. These are olfactory, auditory, and visual cues and signals (David \& Cézilly, 2011; Jennions \& Petrie, 1997; Johansson \& Jones, 2007). The latter may include male behavior (aspects of personality) and size. Like Thom et al. (2004) we found no correlation between paternities and any of the male phenotypic characters (weight and shyness scores), hence these male qualities cannot be used to predict paternity by themselves. However, there was a tendency for the Shyness 2 score from the novel object test in February to correlate negatively with paternity. This Shyness 2 score was related to exploration or curious approach toward a novel object (Noer et al., 2016) with a lower Shyness 2 score indicating a more explorative or curious mink. The negative tendency found in this study suggests that females might choose males, which are more explorative or curious, as the fathers of their offspring. A possible explanation to this is that explorative or curious males interact more with females, through the entrance hole and wire-mesh, and are more willing to approach and mate with a female when she enters his cage, that is, paternity might be a direct result of male personality or an indirect through female choice. We expected sociability (shyness in social contexts) to be a measure of interest in approaching other individuals, but none of these personality measures (Shyness 1 and 2 from the February mirror test), predicted paternity. The simple explanation for this may be that these shyness measures were measured in a mirror test, showing the individuals' willingness to approach same sex conspecifics (their mirror image), and, therefore, might not be related to mate choice and sociability toward the opposite sex. We suggest that future studies on mink should focus on measuring aspects of aggression and shyness-boldness in contexts with opposite sex conspecifics as these might be more relevant for mate compatibility and mate choice.

When we tested the males' shyness-boldness personality scores' and weights' (predictor variables) ability to predict the partner preference measures, we found that Shyness 1 personality measure in the novel object February test predicted a longer mating duration. This shyness measure was speculated to represent coping or fearfulness related to the initial reaction toward the novel object test in Noer et al. (2016). How this coping style can predict longer mating duration is difficult to explain but it might be that more coping animals are better at mating or more preferred by females. In this study, similarities in male and female aspects of shyness could not predict paternity, possibly because the aspects of personality measured in the study by Noer et al. (2016) were not important for mate compatibility as argued in the section above.

Large males are favored by females in many species (Andersson, 1994) since size can be a measure of strength. The sexual size dimorphism in the mink suggests that there might be sexual selection for larger males. The size of males did, however, not seem to predict paternity in this study, maybe because intra- rather than inter-sexual selection can explain the size dimorphism in mink.

\section{3 | Polyandry and timing of matings}

Female mink are polyandrous and may give birth to multiple sired litters both in the wild and on farms (Clausen, Hansen, Weiss, \& Fur, 2012; Dunstone, 1993; Yamaguchi et al., 2004), which was confirmed in this study. All but one female mated with both males and yet only two had shared paternity. The one female that only mated once did not sire any offspring. The two females with shared paternity mated either four times with both males or four and three times with each male, respectively, furthermore one of these females was the only female who spent an equal amount of time sniffing on day 1 to both male samples, which might indicate that the females were unable to make a choice. Thirteen out of 15 females had pups with only one male suggesting that the female mink might be choosy and have the ability to make a choice despite visiting and mating with both males. This result is somewhat surprising because studies in the wild along with studies of farmed mink suggest that entire litters are unlikely to be sired by a single male (Yamaguchi et al., 2004). This difference between the results of our study and those of studies on wild and farmed mink might be explained by different contexts. In the wild females may attempt to get as many matings as possible in order to increase sperm competition or mate with many males as a consequence of avoiding injuries by trying to fight off males. The latter situation is somewhat similar to that of farmed mink where the female is introduced to multiple males one at a time during the breeding season while unable to escape the male. Our study differs from natural and farm conditions as the females can freely choose between males without harassment or forced copulations. The females might have a mechanism to bias the paternity of their offspring toward the preferred male, as polyandry does not preclude pre-copulatory choice by females. Similar studies on American mink and meadow voles (Microtus pennsylvanicus) suggest that polyandrous females do bias matings (Berteaux et al., 1999; Thom et al., 2004).

In this study, we found that the 18 females spent on average 8 out of 10 days visiting males and on average 5 days mating. Most females mated during days 3,9 , and 10 . The increase in number of females mating on days 9 and 10, respectively, might be explained by a renewed interest in mating after the break, where the males were moved to the other side of the females' cage. Seventeen out of 18 females mated with both males and engaged in six matings on average. These activities suggest that the females actively seek out matings with both males and mate multiple times with the same male which might be to increase sperm competition. Thom et al. (2004) suggested that female mink actively choose polyandry, which is supported by this study. However, in this study some females were observed to fight the males and leave male cages without mating, suggesting that the females might have more influence on who they mate with and for how long than previously expected from observations in the wild (Dunstone, 1993). Our findings further suggest that female mink are capable of performing post-copulatory cryptic female choice, making it an advantage to mate with more males (Clutton-Brock \& McAuliffe, 2009). Mating with more males could facilitate sperm competition and thereby enable cryptic female choice of the sperm that provides her 
offspring with the optimal genetic diversity (Clutton-Brock \& McAuliffe, 2009). In the two cases where the females had a litter sired by both males this might be a result of an alternative strategy to increase offspring survival by increasing the genetic diversity between offspring (Yamaguchi et al., 2004). This could be a preferred strategy if the females were unable to determine which male was the better match, and, therefore, were unable to perform a pre-copulatory choice. Other factors affecting this outcome could be male fertility, copulatory vigor, or other male-specific factors.

\section{5 | CONCLUSIONS}

We were able to measure a preference for male urine and feces in all 18 female mink during a 4-day stimulus preference test and in 17 out of 18 females when looking at the first test day only. However, stimulus preference could not predict visiting and mating patterns, probably due to the complex mating patterns of this species and the opportunity for post-copulatory cryptic female choice. The stimulus preference was able to explain paternity in $62-69 \%$ of the female mink and one female with no offspring showed little interest in the male urine and feces samples. Mating duration, which was the best mate preference measure, was able to explain $69 \%$ of the paternity. However, none of these were significant and our results confirm that mate choice is complex and cannot be determined solely on preference tests for urine and feces as all but one female mink chose to mate with both males. Hence other cues and signals seem to play an important role when mates are introduced.

Our results show that females do use the option for mate choice when provided with a choice between two males, since most females only had one father of their offspring but there seem to be a lot of confounding factors affecting the females' decision. This was expected as females in natural settings get more signals and cues to base their mate preference on.

Some zoo breeding programs are unsustainable due to pair incompatibly and breeding failure. Our findings might have interesting implications for zoo breeding programs as urine and feces samples from mates deemed genetically suitable by studbook data could be sent to the female for improving familiarity prior to introduction. However, the results of this study clearly suggest that more signals and cues are needed for the female to make a choice of partner. Therefore, we suggest that future studies should aim at testing multiple signals and cues related to mate choice. Also, ideally breeding managers should strive to provide females in the breeding programs of threatened solitary carnivores a choice of more suitable males whenever possible in order to improve the breeding success of these endangered species in the future.

\section{ACKNOWLEDGMENTS}

We thank Leif Lau Jeppesen and Tine Simonsen for much appreciated exchange of ideas and help, John Bruun Andersen for technical support, Line Sass Kierkegaard, Camilla Boline Hansen, and Mie
Bjerring for help with observations, Esther Kjær Needham and AnnSophie Wiese for help with animal personality tests, as well as Boye Pedersen and Jan Elnif at Rørrendegård research mink farm and Jørgen and Jens Jensen at Åskovgård Mink farm for help and support. Thanks to Innovation Fund Denmark, Ministry of Higher Education and Science, Denmark (Grant number: 12-122917) for funding this research.

\section{CONFLICTS OF INTEREST}

The authors have no conflicts of interest to declare.

\section{ORCID}

Christina Lehmkuhl Noer (iD http://orcid.org/0000-0001-8303-5759

\section{REFERENCES}

Adams, C. E., \& Rietveld, A. A. (1981). Duration of copulation and fertility in the mink, Mustela vison. Theriogenology, 15, 449-452.

Andersson, M., \& Simmons, L. W. (2006). Sexual selection and mate choice. Trends in Ecology \& Evolution, 21, 296-302. https://doi.org/10.1016/j. tree.2006.03.015

Andersson, M. B. (1994). Sexual selection. Princeton, N.J.: Princeton University Press.

Anistoroaei, R., Nielsen, V., Markakis, M. N., Karlskov-Mortensen, P., Jørgensen, C. B., Christensen, K., \& Fredholm, M. (2012). A re-assigned American mink (Neovison vison) map optimal for genome-wide studies. Gene, 511, 66-72. https://doi.org/10.1016/j.gene.2012.08.033

Asa, C. S., Traylor-Holzer, K., \& Lacy, R. C. (2011). Can conservationbreeding programmes be improved by incorporating mate choice? International Zoo Yearbook, 45, 203-212. https://doi.org/10.1111/ j.1748-1090.2010.00123.x

Baker, K., Pullen, P. K., \& Pullen, K. (2013). The Impact of housing and husbandry on the personality of cheetah (Acinonyx jubatus). Journal of Zoo and Aquarium Research, 1, 35-40.

Berejikian, B. A., Tezak, E. P., \& LaRae, A. L. (2000). Female mate choice and spawning behaviour of Chinook salmon under experimental conditions. Journal of Fish Biology, 57, 647-661. https://doi.org/10.1111/j.10958649.2000.tb00266.x

Berteaux, D., Bêty, J., Rengifo, E., \& Bergeron, J.-M. (1999). Multiple paternity in meadow voles (Microtus pennsylvanicus): investigating the role of the female. Behavioral Ecology and Sociobiology, 45, 283-291. https://doi.org/10.1007/s002650050563

Berzins, R., \& Helder, R. (2008). Olfactory communication and the importance of different odour sources in the ferret (Mustela putorius f. furo). Mammalian Biology Zeitschrift für Säugetierkd, 73, 379-387. https://doi.org/10.1016/j.mambio.2007.12.002

Birkhead, T., \& Møller, A. (1993). Female control of paternity. Trends in Ecology \& Evolution, 8, 100-104. https://doi.org/10.1016/0169-5347 (93)90060-3

Clapperton, B. K. (1989). Scent-marking behaviour of the ferret, Mustela furo L. Animal Behavior, 38, 436-446. https://doi.org/10.1016/S00033472(89)80037-5

Clausen, J., Hansen, B. K., Weiss, V., \& Fur, K. (2012). In: Mink 2: Reproduktion, Genetik, Statistik (pp. 8-32), Denmark: Kopenhagen Fur, i samarbejde med Videncentret for Landbrug, Landbrugsforlaget.

Cloe, A. L., Woodley, S. K., Waters, P., Zhou, H., \& Baum, M. J. (2004). Contribution of anal scent gland and urinary odorants to mate 
recognition in the ferret. Physiology \& Behavior, 82, 871-875. https:// doi.org/10.1016/j.physbeh.2004.07.006

Clutton-Brock, T., \& McAuliffe, K. (2009). Female mate choice in mammals. Quarterly Review of Biology, 84, 3-27.

Dallaire, J. A., Meagher, R. K., \& Mason, G. J. (2012). Individual differences in stereotypic behaviour predict individual differences in the nature and degree of enrichment use in caged American mink. Applied Animal Behaviour Science, 142, 98-108. https://doi.org/10.1016/j.applanim.2012.09.012

Dansk Pelsdyravlerforening, Finlands Pälsdjuruppfödares Förbund, Norges Pelsdyralslag, Sveriges Pälsdjursuppfödares Riksförbund, \& Lund, A (1961). Mink: avl og opdræt: nordisk håndbog for minkopdrættere. Denmark: Det Kongelige Danske Landhusholdningsselskab.

David, M., Auclair, Y., \& Cézilly, F. (2011). Personality predicts social dominance in female zebra finches, Taeniopygia guttata, in a feeding context. Animal Behavior, 81, 219-224. https://doi.org/10.1016/j. anbehav.2010.10.008

David, M., \& Cézilly, F. (2011). Personality may confound common measures of mate-choice. PLoS ONE, 6, e24778. https://doi.org/ 10.1371/journal.pone.0024778

Díez-León, M., Bowman, J., Bursian, S., Filion, H., Galicia, D., Kanefsky, J., . . . Mason, G. (2013). Environmentally enriched male mink gain more copulations than stereotypic, barren-reared competitors. PLoS ONE, 8, 1-11. https://doi.org/10.1371/journal.pone.0080494

Dingemanse, N. J., Both, C., Drent, P. J., \& Tinbergen, J. M. (2004). Fitness consequences of avian personalities in a fluctuating environment. Proceedings Biological Sciences, 271, 847-852. https://doi.org/ 10.1098/rspb.2004.2680

Dingemanse, N. J., \& Réale, D. (2005). Natural selection and animal personality. Behaviour, 142, 1159-1184. https://doi.org/10.1163/ 156853905774539445

Drickamer, L., Gowaty, P., \& Holmes, C. (2000). Free female mate choice in house mice affects reproductive success and offspring viability and performance. Animal Behavior, 59, 371-378. https://doi.org/10.1006/ anbe.1999.1316

Dunstone, N. (1993). The mink. London: T \& A D Poyser Ltd.

Erlinge, S., Sandell, M., \& Brinck, C. (1982). Scent-marking and its territorial significance in stoats, Mustela erminea. Animal Behavior, 30, 811-818. https://doi.org/10.1016/S0003-3472(82)80154-1

Fisher, H. S., Swaisgood, R. R., \& Fitch-Snyder, H. (2003). Odor familiarity and female preferences for males in a threatened primate, the pygmy loris Nycticebus pygmaeus: Applications for genetic management of small populations. Naturwissenschaften, 90, 509-512. https://doi.org/ 10.1007/s00114-003-0465-9

Forstmeier, W., \& Birkhead, T. R. (2004). Repeatability of mate choice in the zebra finch: Consistency within and between females. Animal Behavior, 68, 1017-1028. https://doi.org/10.1016/j.anbehav.2004.02.007

Gorman, M. L., \& Trowbridge, B. J. (2013). The role of odor in the social lives of carnivores. In J. L. Gittleman (Ed.), Carnivore behaviour, ecology and evolution (pp. 57-88). Springer Science \& Business Media Dordrecht: University of Tennessee, Knoxville.

Hawkins, C. E., \& Racey, P. A. (2009). A novel mating system in a solitary carnivore: The fossa. Journal of Zoology, 277, 196-204. https://doi.org/ 10.1111/j.1469-7998.2008.00517.x

Hunter, F. M., Petrie, M., Otronen, M., Birkhead, T., \& Møller, A. P. (1993). Why do females copulate repeatedly with one male? Trends in Ecology \& Evolution, 8, 21-26. https://doi.org/10.1016/0169-5347(93)90126-A

Jennions, M. D., \& Petrie, M. (1997). Variation in mate choice and mating preferences: A review of causes and consequences. Biological Reviews of the Cambridge Philosophical Society, 72, 283-327.

Johansson, B. G., \& Jones, T. M. (2007). The role of chemical communication in mate choice. Biological Reviews of the Cambridge Philosophical Society, 82, 265-289. https://doi.org/10.1111/j.1469-185X2007.00009.x

Kiik, K., Maran, T., Nagl, A., Ashford, K., \& Tammaru, T. (2013). The causes of the low breeding success of european mink (Mustela lutreola) in captivity. Zoo Biology, 32, 387-393. https://doi.org/10.1002/ zoo. 21062

Lührs, M. L., \& Kappeler, P. M. (2014). Polyandrous mating in treetops: How male competition and female choice interact to determine an unusual carnivore mating system. Behavioral Ecology and Sociobiology, 68, 879-889. https://doi.org/10.1007/s00265014-1701-3

Martin-Wintle, M. S., Shepherdson, D., Zhang, G., Huang, Y., Luo, B., \& Swaisgood, R. R. (2017). Do opposites attract? Effects of personality matching in breeding pairs of captive giant pandas on reproductive success. Biological Conservation, 207, 27-37. https://doi.org/10.1016/ j.biocon.2017.01.010

Martin-Wintle, M. S., Shepherdson, D., Zhang, G., Zhang, H., Li, D., Zhou, X., ... Swaisgood, R. R. (2015). Free mate choice enhances conservation breeding in the endangered giant panda. Nature Communications, 6, 10125. https://doi.org/10.1038/ncomms10125

Martin, P., \& Bateson, P. (1993). Measuring behaviour an introductory guide (2nd ed). Cambridge, UK: Cambridge University Press.

Mellen, J. D. (1991). Factors influencing reproductive success in small captive exotic felids (Felis spp.): A multiple regression analysis. Zoo Biology, 10, 95-110. https://doi.org/10.1002/zoo.1430100202

Mossotti, R. H. (2010). Female reaction to male urine scents as potential indicator of mate choice in captive cheetahs (Acinonyx jubatus). Theses. Paper 237. Southern Illinois University Carbondale.

Murphy, B. D., \& Douglas, D. A. (1992). Reproduction in female mink. In A.H. Tauson, M. Valtonen \& Nordiske Jordbrugsforskeres Forening (Eds.), Reproduction in carnivorous fur bearing animals (pp. 39-49). Copenhagen: Nordiske Jordbrugsforskeres Forening.

Noer, C. L., Needham, E. K., Wiese, A.-S., Balsby, T. J. S., \& Dabelsteen, T. (2016). Personality matters: Consistency of inter-individual variation in shyness-boldness across non-breeding and pre-breeding season despite a fall in general shyness levels in framed American mink (Neovison vison). Applied Animal Behaviour Science, 3, 191-199. https:// doi.org/10.1007/s13398-014-0173-7.2

Noer, C. L., Needham, E. K., Wiese, A.-S., Balsby, T. J. S., \& Dabelsteen, T. (2015). Context matters: Multiple novelty tests reveal different aspects of shyness-boldness in farmed american mink (Neovison vison). PLoS ONE, 10, 1-14. e0130474. https://doi.org/10.1371/ journal.pone.0130474

Penn, D. J., \& Potts, W. K. (1999). The evolution of mating preferences and major histocompatibility complex genes. American Naturalist, 153, 145-164.

Roberts, S. A., Davidson, A. J., Beynon, R. J., \& Hurst, J. L. (2014). Female attraction to male scent and associative learning: The house mouse as a mammalian model. Animal Behavior, 97, 313-321. https://doi.org/ 10.1016/j.anbehav.2014.08.010

Roberts, S. C., \& Gosling, L. M. (2004). Manipulation of olfactory signaling and mate choice for conservation breeding: A case study of harvest mice. Conservation Biology, 18, 548-556. https://doi.org/10.1111/ j.1523-1739.2004.00514.x

Roberts, S. C., \& Gosling, L. M. (2003). Genetic similarity and quality interact in mate choice decisions by female mice. Nature Genetics, 35, 103-106. https://doi.org/10.1038/ng1231

Seton, E. T. (1909). Volume II flesh-eaters-Order carnivora XXXIX. Mink. In: Life-histories of northern animals. New York City: Charles Scribner's sons (pp. 872-900).

Sih, A., \& Watters, J. (2005). The mix matters: Behavioural types and group dynamics in water striders. Behaviour, 142, 1417-1431. https://doi. org/10.1163/156853905774539454

Sundqvist, C., Amador, A. G., \& Bartke, A. (1989). Reproduction and fertility in the mink (Mustela vison). Journals of Reproduction and Fertility, 85, 413-441.

Swaisgood, R., Lindburg, D., Zhou, X., \& Owen, M. (2000). The effects of sex, reproductive condition and context on discrimination of conspecific 
odours by giant pandas. Animal Behavior, 60, 227-237. https://doi.org/ 10.1006/anbe.2000.1464

Thom, M., \& Hurst, J. (2004). Individual recognition by scent. Annales Zoologici Fennici, 41, 765-787.

Thom, M., Macdonald, D., \& Mason, G. (2004). Female American mink, Mustela vison, mate multiply in a free-choice environment. Animal Behavior, 67, 975-984.

Watters, J. V., \& Powell, D. M. (2011). Measuring animal personality for use in population management in zoos: Suggested methods and rationale. Zoo Biology, 12, 1-12. https://doi.org/10.1002/zoo.20379

Wilson, D. S., Clark, A. B., Clark, A., Coleman, K., \& Dearstyne, T. (1994). Shyness and boldness in humans and other animals. Trends in Ecology \& Evolution, 9, 442-446.

Wolf, K. N., Wildt, D. E., Vargas, A., Marinari, P. E., Ottinger, M. A., \& Howard, J. G. (2000). Reproductive inefficiency in male black-footed ferrets (Mustela nigripes). Zoo Biology, 19, 517-528. https://doi.org/ 10.1002/1098-2361(2000)19:6<517::AID-ZOO4>3.0.CO;2-V

Yamaguchi, N., Sarno, R. J., Johnson, W. E., O'Brien, S. J., \& Macdonald, D. W. (2004). Multiple paternity and reproductive tactics of free-ranging american minks, Mustela vison. Journal of Mammalogy,
85, 432-439. https://doi.org/10.1644/1545-1542(2004)085<0432: MPARTO >2.0.CO;2

Zahavi, A. (1975). Mate selection-A selection for a handicap. Journal of Theoretical Biology, 53, 205-214. https://doi.org/10.1016/0022-5193 (75)90111-3

Zhang, G., Swaisgood, R. R., \& Zhang, H. (2004). Evaluation of behavioral factors influencing reproductive success and failure in captive giant pandas. Zoo Biology, 23, 15-31. https://doi.org/10.1002/zoo.10118

How to cite this article: Noer CL, Balsby TJS, Anistoroaei R, Stelvig M, Dabelsteen T. Mate choice screening in captive solitary carnivores: The role of male behavior and cues on mate preference and paternity in females of a model species, American mink (Neovison vison). Zoo Biology.

2017;36:367-381. https://doi.org/10.1002/zoo.21383 